\title{
Kömür Zenginleștirmenin Piroliz Ürün Verimlerine Etkisinin Araştırılması
}

\author{
Aydan AKSOĞAN KORKMAZ ${ }^{*}$, İsmail BENTLI ${ }^{2}$ \\ ${ }^{1}$ Maden Teknolojisi Bölümü, Malatya MYO, İnönü Üniversitesi, Malatya, Türkiye \\ ${ }^{2}$ Maden Mühendisliği Bölümü, Mühendislik Fakültesi, İnönü Üniversitesi, Malatya, Türkiye \\ ${ }^{* 1}$ aydan.korkmaz@inonu.edu.tr, ${ }^{2}$ ismailbentli@gmail.com
}

\section{(Geliș/Received: 19/12/2018;}

Kabul/Accepted: 02/04/2019)

Öz: Bu çalışmada Sivas-Kangal linyiti kullanılarak; öncelikle tüvenan, daha sonra ise Reichert spirali ile zenginleştirilen kömürün pirolizi gerçekleştirilmiştir. Piroliz sonucunda elde edilen katı, sıvı ve gaz ürün verimleri hesaplanarak karşılaştırılmıştır. Optimum piroliz şartlarını belirlemek amacıyla $200 \mathrm{ml} / \mathrm{dk} \mathrm{N} \mathrm{N}_{2}$ gazı akışı ve $3^{\circ} \mathrm{C} / \mathrm{dk}$ 1sıtma hızı sabit tutularak; farklı tane boyutu, sıcaklık ve piroliz süreleri ile deneyler gerçekleştirilmiş̧ir. Belirlenen optimum şartlarda, lavenin de pirolizi yapılmıştır. Deneyler sonucunda tüvenan kömüre göre, zenginleştirilmiş kömürün (lave) çar veriminin $\% 14,26$ azaldığı, buna karşılık sıvı ürün veriminin \%11,97 ve gaz ürün veriminin ise \%2,29 arttı̆ğ hesaplanmıştır. Lave kömürün çarında kül içeriği azalırken, sabit karbon içeriği ve kalorifik değerinin arttığı belirlenmiştir. Zenginleştirme işleminin sıvı ürün verimi ve çar ürünün kalitesini olumlu yönde etkilediği sonucuna varılmıştır.

Anahtar kelimeler: Linyit, piroliz, zenginleştirme, çar, semi-kok.

\section{Investigation of the Effect of Coal Enrichment on Pyrolysis Product Yields}

\begin{abstract}
In this study; the pyrolysis of coal which is firstly raw and then enriched by Reichert spiral was carried out using Sivas-Kangal lignite. The solid, liquid and gas product yields obtained as a result of pyrolysis have been calculated and compared. In order to determine optimum conditions in pyrolysis studies $200 \mathrm{ml} / \mathrm{min} \mathrm{N}_{2}$ gas flow and $3^{\circ} \mathrm{C} / \mathrm{min}$ heating rate have been kept constant and different particle size, temperature and pyrolysis times have been tried. In the optimum conditions, clean coal was also pyrolyzed. As a result of the pyrolysis of clean coal, the char yield has decreased compared to the raw coal by $14.26 \%$, while the liquid yield and gas yield have increased by $11.97 \%, 2.29 \%$, respectively. It has been determined that while the ash content of the clean coal has reduced, the fixed carbon content and calorific value have increased. As a result, it has been concluded that the enrichment has a positive effect on the liquid yield and char product quality.
\end{abstract}

Key words: Lignite, pyrolysis, enrichment, char, semi-coke.

\section{Giriș}

Piroliz, oksijensiz ortamda 1sıtma yoluyla özellikle kömür gibi fosil yakıtlardan gaz, sıvı ve katı ürünler üretme prosesinin genel adıdır. Bu proses, aynı zamanda karbonizasyon olarak da isimlendirilmektedir [1]. Piroliz, genellikle hava veya diğer bazı gazların varlığında kömürün termal bozunması olarak tanımlanmaktadır [2]. Kullanılan sıcaklığa bağlı olarak $500^{\circ} \mathrm{C}-600^{\circ} \mathrm{C}$ düşük sıcaklık pirolizi veya semi-karbonizasyon, $900^{\circ} \mathrm{C}$ $1100^{\circ} \mathrm{C}$ ise yüksek sıcaklık pirolizi veya koklaşma olarak adlandırılmaktadır. Yüksek sıcaklık karbonizasyonunun temel amacı metalürjik kok üretmektir. Düşük sıcaklık karbonizasyonu ise, sokakların aydınlatılmasında, kimya sanayinde (hammadde), yerel ve endüstriyel amaçlı dumansız yakıt eldesinde kullanılmaktadır $[3,4]$.

Piroliz yüksek kaliteli katı ürün (çar) veya bir takım gaz ve sıvı ürünler elde edebilmek için yapılan en önemli termal dönüşüm proseslerinden biridir [1]. Karbonizasyonla sıvı ve gaz yakıt üretilerek, içten yanmalı motorlar için sentetik yakıt elde edilebilmekte, katı yakıtlardaki kükürtten oluşan çevre kirliliği de önlenebilmektedir. Karbonizasyon işlemi ayrıca kok üretimi ve briketleme amaçları için de uygulanmaktadır [5].

Pirolizde önemli proses değişkenlerinden biri sıcaklıktır. En yüksek katran veriminin elde edildiği sıcaklık, kömürün rankına ve oluşan katranın kararlılığına bağlı olarak değişmektedir. Bu sıcaklıktan daha yüksek sicaklıklarda da, gaz tepkimeye girmeye devam etmekte ve toplam uçucu bileşik verimi de artan sicaklığa paralel olarak artmaktadır. Piroliz sıcaklığı, uçucu maddenin miktar ve bileşimini etkileyen önemli bir parametredir. Sıvı, gaz ve katı miktarları piroliz sıcaklığı ile değişmekte ve bunların kimyasal bileşimleri de oldukça farklı olmaktadır [6].

\footnotetext{
* Sorumlu yazar: aydan.korkmaz@inonu.edu.tr Yazarların ORCID Numarası: ${ }^{1}$ 0000-0002-3309-9719, ${ }^{2}$ 0000-0003-3775-7341
} 
Bir diğer önemli değişken piroliz süresidir. Piroliz süresi, piroliz işlemi sırasında oluşan buhar fazdaki ürünlerin piroliz ortamında tutulma süresidir. Eğer piroliz işleminde hedeflenen ürün katı ürün ise, atık yavaş piroliz (karbonizasyon) işlemine tabi tutulmalıdır. Uzun piroliz sürelerinde, uçucu ürünlerin bozunduğu ve karbon içeren atığın tekrar gazlaştığı gözlenmektedir. Kısa alıkonma zamanlarında yapılan piroliz işlemlerinde ise, işlem sıcaklığı ile kimyasal bileşim arasında bir bağlantı olduğu görülmektedir. Sıcaklık arttıkça, maddenin yapısındaki oksijen içeriği ve H/C oranı azalmaktadır $[6,7]$.

Kömürün tane büyüklüğü de pirolizi etkileyen önemli bir faktördür. Parçacık boyutunun artması ile pirolizle oluşan uçucuların gaz atmosferine geçiş yolu uzamaktadır. Diğer bir ifadeyle, kütle transferi sınırlaması söz konusu olmaktadır. Bu nedenle, uçucular yüzeyle daha uzun süre temas etmektedirler ve bu da ikincil reaksiyonların oluşmasına ve diğer ürünlere dönüşüme neden olmaktadır. Bunların başlıcaları; uçucuların çeşitli yüzey etkileşimi sonucu koklaşma reaksiyonlarına girip, yeniden polimerize olmaları veya sıcak katı yüzeylerde çeşitli parçalanma reaksiyonlarına uğramalarıdır. Koklaşma tüm piroliz verimini düşürürken, yüzeyde parçalanma reaksiyonları sıvı verimini azaltıp, gaz verimini arttırma yönünde etki etmektedir. Ayrıca piroliz ortamında sürükleyici gaz kullanarak kütle transferi sınırlamasını ortadan kaldırmak mümkündür [7].

Literatürde, zenginleştirmenin karbonizasyon/piroliz ürün verimlerine etkisiyle ilgili herhangi bir çalışmaya rastlanmamıştır. Bu çalışmada, linyitin pirolizi sonucunda oluşan çar (semi-kok), katran (sıvı) ve gaz ürünlerin verimleri hesaplanmıştır. Daha sonra, zenginleştirme sonucunda ürün verimlerinin değişimine bakılmıştır. Bu bağlamda, çalışma alanında bir ilk olma özelliği taşımaktadır.

\section{Materyal ve Yöntem}

Çalışmada kullanılan Kangal linyiti, draglaynın döküm basamağından ve ocak içinden muhtelif damarlardan belirli periyotlarla yeteri kadar alınmıştır. Havada kurutulan linyit örnekleri, konileme-dörtleme yöntemiyle azaltılmış ve Jones Riffle örnek bölücüyle yaklaşık 2,5 kg’lık kısımlara ayrıldıktan sonra deneylerde kullanılmak üzere kapalı naylon poşetlere konulmuştur. Tüm analizler ve deneyler havada kuru bazda gerçekleştirilmiştir.

Karakterizasyon çalışmaları için linyit örnekleri, laboratuvar tip tek istinat kollu çeneli kırıcıyla $30 \mathrm{~mm}$ altına kırıldıktan sonra Fritsch marka çekiçli kırıcı ile $3 \mathrm{~mm}$ altına kırılmış, yatay döndürmeli çelik bilyalı değirmen ve Retsch marka halkalı değirmen ile öğ̈̈tülerek $38 \mu \mathrm{m}$ boyutunun altına indirilmiştir [8].

Linyit örneğinin yüzey nemi ASTM D1412'ye göre, oda sıcaklığında sabit tartıma gelene kadar bekletilerek hesaplanmıştır. Bünye rutubeti içeriği ASTM D3173'e göre, 0,25 mm'nin altına öğütülmüş havada kuru kömür numunesinin, sıcaklığı iyi kontrol edilebilen ve içinde kuru hava sirkülasyonu olan bir etüvde 104$110^{\circ} \mathrm{C}$ 'de, 1 saat süreyle bekletildikten sonra, uğradığı ağırlık kaybından yararlanılarak saptanmıştır. Kül analizi ASTM D3174' e göre, 0,25 mm'nin altına ögütülmüş 1 g'lık kömür numunesinin, yavaş yavaş $700-750^{\circ} \mathrm{C}^{\prime} y e$ çıkarılan hava sirkülasyonlu bir firında 1sıtılarak, ağırlı̆̆ sabit kalana kadar $( \pm 0,001 \mathrm{~g})$ bekletilmesiyle yapılmıştır. Kül miktarı, kalan kütlenin tartılması sonucu saptanmıştır. Uçucu madde içeriği ASTM D3175'e göre, 1g'lık kömür numunesinin kapaklı bir platin krozede, dikey bir boru firında $950 \pm 20^{\circ} \mathrm{C}$ 'de 7 dakika tutulduktan sonra uğradığı ağırlık kaybından saptanmıştır. Kömür örneklerinin sabit karbon içerikleri ise; nem, kül ve uçucu madde içerikleri toplamının 100'den çıkarılmasıyla hesaplanmıştır. Toplam kükürt miktarı elementel analiz yönteminde kullanılan LECO marka CHNS-932 cihazıyla, kalorifik değeri ise IKA C1 marka kalorimetre bombasıly belirlenmiştir.

XRD, FTIR ve elementel analizleri İnönü Üniversitesi Bilimsel ve Teknolojik Araştırma Merkezi’nde (İBTAM), termal analizler (DTA-TGA) ise İnönü Üniversitesi Kimya Bölümü Labaratuvarında yaptırılmıştır. XRD analizi için Rigaku D Max 2B cihazı, FTIR analizi için Varian 1000 FT-IR cihazı ve termal karakteristiklerini belirlemek amaciyla da SHIMADZU Differantial Thermal Analyser DTA-50 ve SHIMADZU Thermogravimetric Analyser TGA-50 model cihazlar kullanılmıştır.

Zenginleştirme çalışmalarında kül ve kükürt uzaklaştırması amacıyla, Denver HG-7D model Reichert spirali kullanılmıştır. Spiral deneyleri için linyit örnekleri ilk aşamada çeneli kırıcıyla $30 \mathrm{~mm}$ altına, ikinci aşamada çekiçli kırıcı ile $3 \mathrm{~mm}$ altına kırıldıktan sonra $-3,35+2 \mathrm{~mm},-2+1,18 \mathrm{~mm}$ ve $-1,18+0,15 \mathrm{~mm}$ olmak üzere 3 boyut grubuna ayrılmıştır. $-0,15 \mathrm{~mm}$ boyutu ise şlam oluşturmasını önlemek ve yüksek kül içerdiğinden dolayı deneye alınmamıștır. Hazırlanan 3 farklı boyut grubu ile, pülpte katı oranı (\%7,5, \%15, \%25 ve \%35) ve ayırma bıçak konumu $\left(90^{\circ}, 120^{\circ}\right.$ ve $\left.150^{\circ}\right)$ deneyleri gerçekleştirilmiştir. Bu deneyler sonucunda kül ve kükürt içeriğinin en az olduğu zenginleştirme ürünü (en temiz lave), piroliz deneylerinde kullanılmıştır [8].

Piroliz deneyleri için linyit örnekleri çeneli kırıcıyla $30 \mathrm{~mm}$ altına indirildikten sonra Vommak marka merdaneli kırıcıdan kırılarak kapalı devre halinde tamamı 4,75 mm, 3,35 mm ve 1,18 mm altına indirilene kadar geçirilmiştir. Piroliz çalışmalarında Şekil 1'de verilen Protherm PZF model çok zonlu tüp firın kullanılarak, 200 
$\mathrm{ml} / \mathrm{dk} \mathrm{N}_{2}$ gazı akışı ve $3^{\circ} \mathrm{C} / \mathrm{dk}$ 1sıtma hızı sabit tutularak optimum tane boyutu, sıcaklık ve piroliz süresi belirlenmiştir. Optimum tane boyutunu belirlemek amaciyla numunelerin tamamı 4,75 mm, 3,35 mm ve 1,18 $\mathrm{mm}$ tane boyutlarının altına indirilerek, $500^{\circ} \mathrm{C}$ 'de 30 dakika süreyle piroliz deneyleri yapılmıştır. Optimum sicaklığ 1 belirlemek amaciyla belirlenen tane boyutunda 30 dakika süreyle, $400^{\circ} \mathrm{C}, 500^{\circ} \mathrm{C}, 600^{\circ} \mathrm{C}, 700^{\circ} \mathrm{C}$ ve $800^{\circ} \mathrm{C}$ sicaklıklarda piroliz deneylerine devam edilmiştir. Son aşamada ise belirlenen tane boyutu ve sicaklıkta 15, 30, 45 ve 60 dakika piroliz süreleri deneyleri gerçekleştirilmiştir [8].

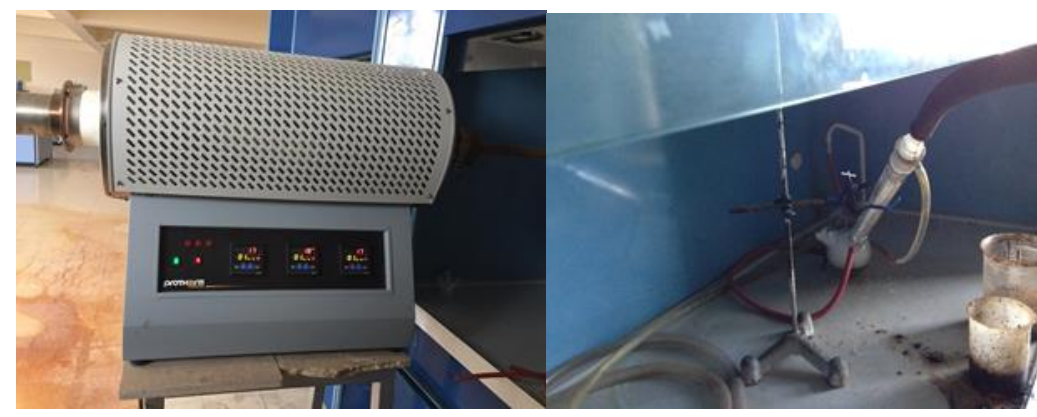

Şekil 1. Piroliz deneylerinde kullanılan tüp firın

Çar (katı kalıntı), sıvı, gaz verimleri ve toplam dönüşüm oranlarının hesaplanmasında kullanılan eşitlikler (1)-(4)'de verilmiştir;

$$
\begin{aligned}
& \text { Katı (Çar) verimi: } \\
& \% \text { Katı }=\frac{\text { Katı miktarı }(\mathrm{g})}{\text { Toplam örnek miktarı }(\mathrm{g})} \times 100
\end{aligned}
$$

Sivı verimi:

$\%$ Sıvı $=\frac{\text { Sıvı miktarı }(\mathrm{g})}{\text { Toplam örnek miktarı (g) }} \times 100$

Gaz verimi:

$\% \mathrm{Gaz}=\frac{\text { Toplam örnek miktarı }(\mathrm{g})-[\text { Katı miktarı }(\mathrm{g})+\text { Sıvı miktarı }(\mathrm{g})]}{\text { Toplam örnek miktarı }(\mathrm{g})} \times 100$

Toplam dönüşüm oranı:

\%Toplam Dönüşüm $=\frac{\text { Toplam örnek miktarı }(\mathrm{g})-\text { Katı miktarı }(\mathrm{g})}{\text { Toplam örnek miktarı }(\mathrm{g})} \times 100$

\section{Araştırma Bulguları ve Tartışma}

Kangal linyitinin havada kuru bazda gerçekleştirilen kısa analiz ve elementel analiz sonuçlarına göre hesaplanan orijinal, kuru ve kuru-külsüz baz değerleri Tablo 1'de verilmiştir.

Orijinal nem oranı \%45,91 olan Kangal linyiti yumuşak linyit sınıfına girmektedir. Ayrıca Kangal linyitinin orijinal bazda kaba nem miktarının \%42,56 ve külünün \%25,08 olması genç linyit olduğunun diğer göstergeleridir [9]. Kangal linyiti için hesaplanan baz değerleri literatür ile uyumludur [10, 11]. Kangal linyit örneğinin XRD analizi sonucu (Şekil 2) incelendiğinde, linyit yapısında illit (kil minerali) $\left(\mathrm{K}, \mathrm{H}_{3} \mathrm{O} / \mathrm{H}_{2} \mathrm{O}\right) \mathrm{Al}_{2}$ $\left[(\mathrm{OH})_{2} / \mathrm{AlSi}_{3} \mathrm{O}_{10}\right]$, kalsit $\left(\mathrm{CaCO}_{3}\right)$ ve pirit $\left(\mathrm{FeS}_{2}\right)$ minerallerine ait pikler belirlenmiştir.

Piroliz deneyleri azot $\left(\mathrm{N}_{2}\right)$ gazı ortamında gerçekleştirildiğinden, Kangal linyitinin azot ortamında DTATGA değişimi Şekil 3'de verilmiştir. DTA eğrisinde 3 bölge görülmektedir. Termogram eğrisinde yaklaşı $17^{\circ} \mathrm{C}$ ve $145^{\circ} \mathrm{C}$ 'lerde görülen kaba nem ve bünye nemine bağlı olan pikler 1.bölgeyi, $394^{\circ} \mathrm{C}$ 'de başlayan ve $664^{\circ} \mathrm{C}$ civarında biten uçucu madde çıkışı 2.bölgeyi, karbonat parçalanma başlangıç sıcaklığı olan $701^{\circ} \mathrm{C}$ 'deki pik 3.bölgeyi göstermektedir. 
Kömür Zenginleştirmenin Piroliz Ürün Verimlerine Etkisinin Araştırılması

Tablo 1. Kangal linyitinin kısa ve elementel analiz sonuçları

\begin{tabular}{|l|c|c|c|c|}
\hline Kısa analiz & Orijinal baz & $\begin{array}{c}\text { Havada kuru } \\
\text { baz }\end{array}$ & Kuru baz & $\begin{array}{c}\text { Kuru-külsüz } \\
\text { baz }\end{array}$ \\
\hline Kaba nem (\%) & 42,56 & - & - & - \\
\hline Nem (\%) & 45,91 & 5,83 & 0 & - \\
\hline Kül (\%) & 25,08 & 43,66 & 46,36 & - \\
\hline Uçucu madde (\%) & 18,03 & 31,91 & 33,89 & 63,18 \\
\hline Sabit C (\%) (fark ile) & 10,98 & 18,60 & 19,75 & 36,82 \\
\hline Toplam S (\%) & 1,69 & 2,94 & 3,12 & - \\
\hline AID (kcal/kg) & 1387 & 2860 & 3074 & 5662 \\
\hline Elementel analiz & \multicolumn{5}{|l}{} \\
\hline C (\%) & - & 22,81 & 24,22 & 45,16 \\
\hline H (\%) & - & 2,8 & 2,97 & 5,54 \\
\hline N (\%) & - & 0,36 & 0,38 & 0,71 \\
\hline S (\%) & - & 2,95 & 3,13 & 5,84 \\
\hline O (\%) (fark ile) & - & 71,08 & 69,30 & 42,75 \\
\hline
\end{tabular}

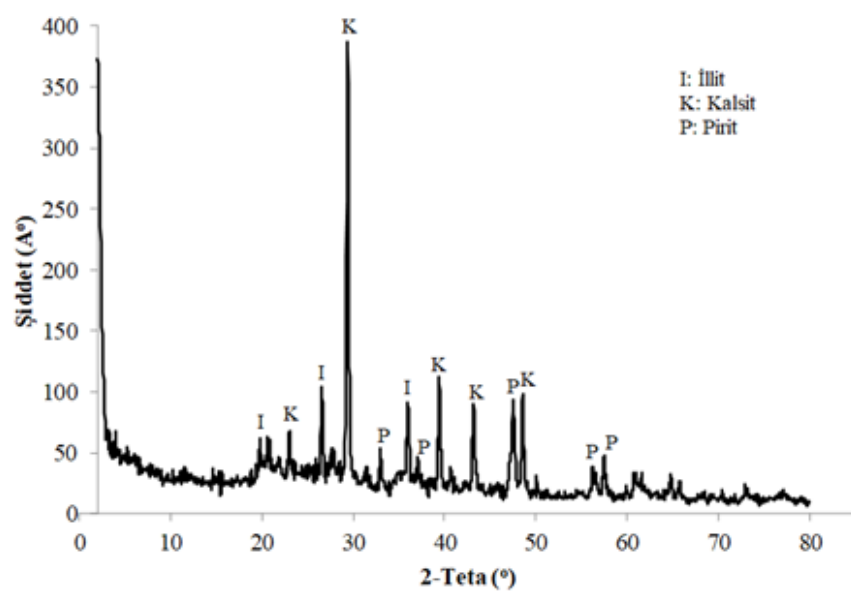

Şekil 2. Kangal linyitinin XRD analiz sonucu

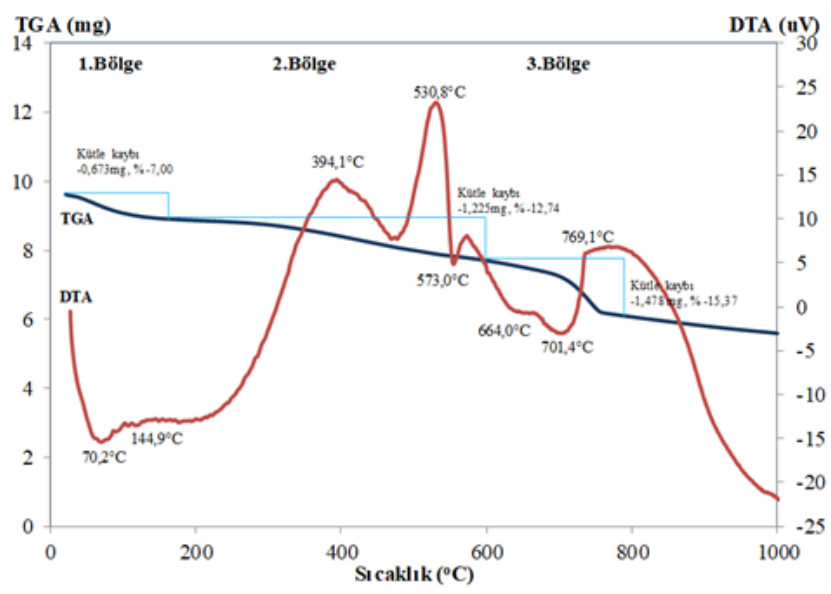

Şekil 3. Kangal linyitinin azot atmosferinde sıcaklığa bağlı olarak termal gravimetri değiş̧imi 
Tüm tane boyutlarındaki örnekler için bıçak açıklığı sabit tutularak, pülpte katı oranı değiştirilmiş ve elde edilen Reichert spiral sonuçları Şekil 4'de verilmiştir. Şekil 4a'dan Reichert spirali ile gerçekleştirilen tüm boyut gruplarında, katı oranına bağlı olarak kül ve yanabilir verim değişimlerinin benzer eğilim gösterdiği görülmüştür. Tüm tane boyutlarında \%25 katı oranında en düşük lave külleri ve en yüksek yanabilir verimler elde edilmiştir. Şekil 4b'den tane boyutunun azaltılmasına ve piritik kükürt serbestleşmesine bağlı olarak hem lave kükürdünde azalma, hem de toplam kükürt uzaklaştırma veriminde artış olduğu belirlenmiştir. Tane boyutlarına ait lavelerin birleştirilmesiyle, \%2,94 S içeren besleme linyitinden \%57,6 kükürt uzaklaştırma verimiyle \%1,82 S içeren lave kazanılmıştır. Deneyler sonucunda \%25 katı oranının optimum katı oranı olarak seçilmesine karar verilmiştir. Seçilen katı oranı literatür ile uyumludur $[12,13]$.

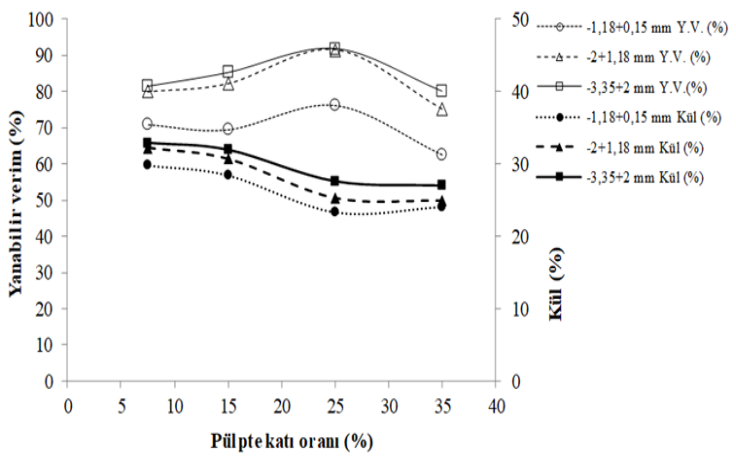

(a)

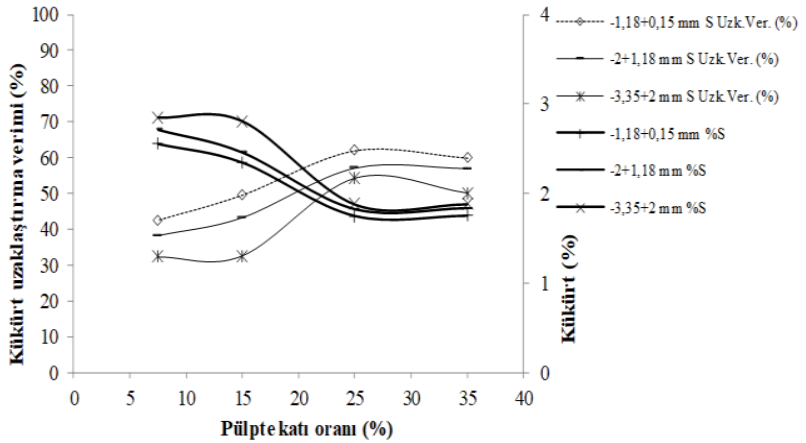

(b)

Şekil 4. Reichert spiralinde, $150^{\circ}$ bıçak açıklığında tane boyutlarına göre, pülpte katı oranına bağlı olarak kül ve yanabilir verim değişimi/ kükürt ve kükürt uzaklaştırma verim değişimi

Pülpte katı oranı belirlendikten sonra, lave bıçak ayarları $90^{\circ}$ ve $120^{\circ}$ olacak şekilde değiştirilerek deneylere devam edilmiştir. Bıçak ayarlarının değişimine göre elde edilen deney sonuçları Şekil 5'de gösterilmiştir.

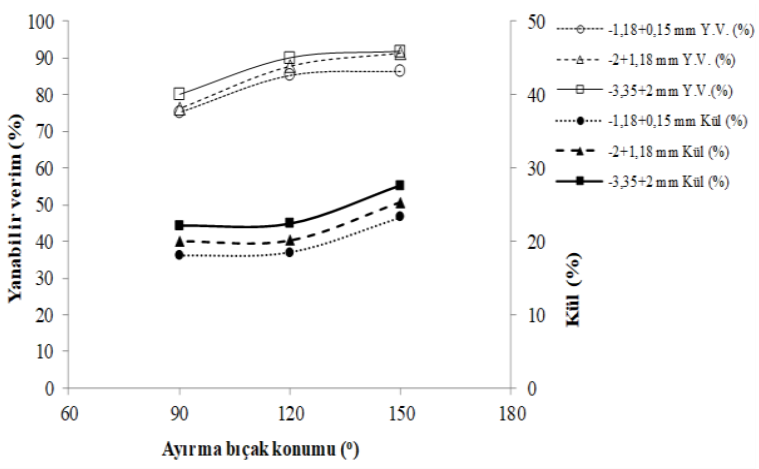

(a)

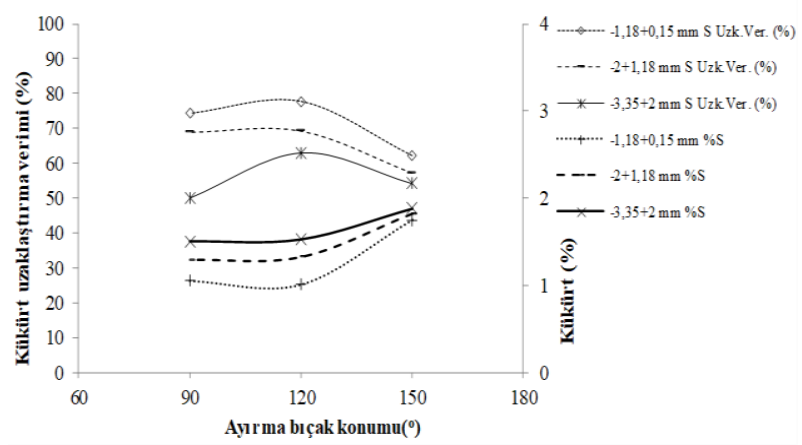

(b)

Şekil 5. Reichert spiralinde, \%25 katı oranında tane boyutlarına göre, bıçak konumuna bağlı olarak kül ve yanabilir verim değişimi/ kükürt ve kükürt uzaklaştırma verim değişimi

Şekil 5a'dan görüldüğü gibi tüm tane boyutlarında en düşük lave kül değerleri $90^{\circ}$ 'lik bıçak konumunda olmasına rağmen, düşük yanabilir verimlerinden dolayı $120^{\circ}$ bıçak açıklığının seçilmesinin uygun olduğuna karar verilmiştir. Şekil 5b'den ayırıcı bıçağın $90^{\circ}$ ve $120^{\circ}$ konumlarında tüm boyutlarda kükürt içeriği birbirine yakınken, kükürt uzaklaştırma verimlerinin $120^{\circ}$ de daha iyi olduğu belirlenmiştir. Bundan dolayı $120^{\circ}$ bıçak açıklığı tercih edilmiştir. Deneyler sonucunda \%43,66 kül içeren besleme linyitinden, \%87,75 yanabilir verimle $\% 20,41$ küllü lave elde edilmiştir. Beslemede \%2,94 olan kükürt içeriğinin lavede \%1,29 olduğu, dolayısıyla kükürdün yaklaşık \%70'nin giderildiği belirlenmiştir. Elde edilen bu lave, daha sonra piroliz deneylerinde kullanılmıştır. 
Piroliz deneylerinde çalıșılacak tane boyutunu belirleyebilmek amacıyla, $-4,75 \mathrm{~mm},-3,35 \mathrm{~mm}$ ve $-1,18 \mathrm{~mm}$ boyutlu kömür numuneleri ile, $200 \mathrm{ml} / \mathrm{dk} \mathrm{N}_{2}$ gazı akışında, $3^{\circ} \mathrm{C} / \mathrm{dk}$ 1sıtma hızıyla, $500^{\circ} \mathrm{C}$ 'de 30 dakika süreyle piroliz deneyleri yapılmıştır. Kangal linyitinin piroliz deneylerinin tane boyutuna göre ürün verimi değişimleri ve kısa analiz sonuçları Şekil 6'da verilmiştir.

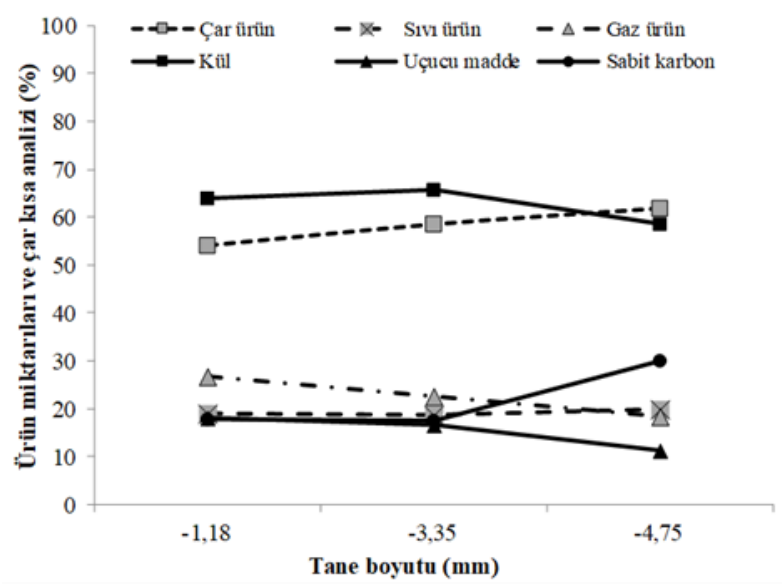

Şekil 6. $500^{\circ} \mathrm{C}$ sıcaklık ve 30 dakika piroliz süresinde farklı tane boyutlarında ürün verimleri ve çar kısa analiz değişimi

Şekil 6 incelendiğinde linyit için en uygun tane boyutunun $-4,75 \mathrm{~mm}$ olduğu görülmüştür. Bu boyutta \%61,70 çar, \%19,92 sıv1 ve \%18,38 gaz verimi elde edilmiştir. Beslemenin sabit karbonu \%18,60’dan \%30,13'e yükselmiştir. Bundan sonraki aşamalarda piroliz tane boyutu olarak 4,75 mm altı kullanılmıştır.

$-4,75 \mathrm{~mm}$ tane boyutunda $400^{\circ} \mathrm{C}, 500^{\circ} \mathrm{C}, 600^{\circ} \mathrm{C}, 700^{\circ} \mathrm{C}$ ve $800^{\circ} \mathrm{C}$ 'de piroliz deneyleri gerçekleştirilmiştir. Piroliz sıcaklığına ait deney sonuçları Şekil 7'de verilmiştir. Şekil 7'den görüldüğü gibi literatüre uygun olarak piroliz sıcaklığı arttıkça, çar ürün verimi azalırken sıvı ve gaz ürün verimleri artış göstermiştir [14-17]. Çar veriminin ve buna bağlı olan sabit karbon içeriğinin yüksek ve nispeten çar külünün az olduğu $500^{\circ} \mathrm{C}^{\prime}$ nin piroliz sıcaklığı olarak alınmasına karar verilmiştir.

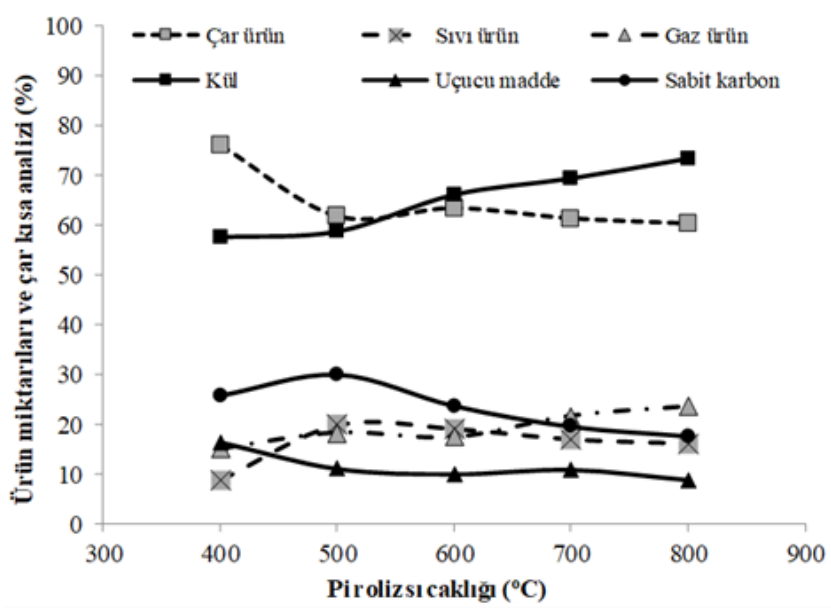

Şekil 7. -4,75 mm tane boyutu ve 30 dakika piroliz süresinde farklı sıcaklıklarda ürün verimleri ve çar kısa analizi değişimi

Fırın $500^{\circ} \mathrm{C}^{\prime}$ ye ulaştıktan sonra $15,30,45$ ve 60 dakika süreyle bekletilen numunelerin piroliz deney sonuçları Şekil 8'de gösterilmiştir. Şekil 8'den, Kangal linyitinin $500^{\circ} C^{\prime}$ de piroliz süresinin 30 dakika seçilmesinin uygun olduğu düşünülmüştür. 
Piroliz deneyleri sonucunda, Kangal linyiti için $-4,75 \mathrm{~mm}$ tane boyutu, $500^{\circ} \mathrm{C}$ piroliz sıcaklığ 1 ve 30 dakika piroliz süresinin optimum piroliz şartları olarak seçilmesine karar verilmiştir.Bundan sonra çalışmanın esasını oluşturan zenginleştirme yönteminin piroliz ürünlerine etkisini belirlemek amacıyla, Reichert spiralinden elde edilmiş lavenin, belirlenen optimum çalışma şartlarında piroliz deneyleri gerçekleştirilmiştir. Piroliz deneylerinin tüvenan linyite göre karşılaştırılması Şekil 9’da verilmiştir.

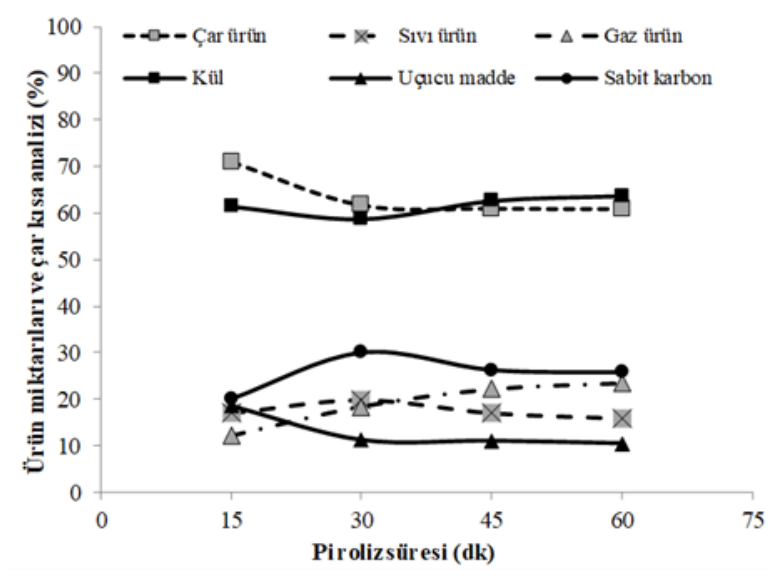

Şekil 8. $-4,75 \mathrm{~mm}$ tane boyutunda ve $500^{\circ} \mathrm{C}$ sıcaklıkta farklı piroliz sürelerinde ürün verimleri ve çar kısa analiz değişimi

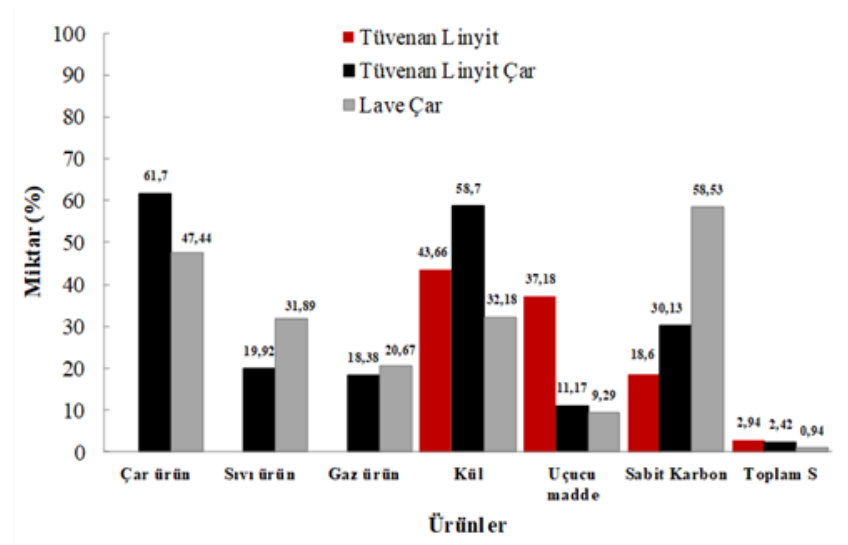

Şekil 9. Tüvenan linyit, tüvenan çar ve lave çarın piroliz ürün verimleri ve kısa analiz değişimleri

Şekil 9 incelendiğinde, Kangal linyitinin Reichert spirali zenginleştirilmesiyle yapılan piroliz deneylerinde, tüvenan Kangal linyitine göre çar üründe \%14,26 azalma, sıvı üründe \%11,97 ve gaz üründe ise \%2,29 artış olduğu tespit edilmiştir. Çar ürünün kısa analizinde kül içeriği \%58,70’ten \%32,18'e azalırken, sabit karbonun içeriği \%30,13'den \%58,53'e yükselmiştir. Linyitin pirolizi sonucunda elde edilen çar ürünün kalorifik değeri kuru-külsüz bazda $8820 \mathrm{kcal} / \mathrm{kg}$ iken, lave ürünün pirolizi sonucunda kalorifik değer $9240 \mathrm{kcal} / \mathrm{kg}$ 'ye yükselmiştir. Bu durumda kalori değerinde yaklaşık $420 \mathrm{kcal} / \mathrm{kg}$ 'lik bir artı̧̧ olduğu belirlenmiştir. Linyitin tüvenan ve lave halde piroliz edilmesiyle çar üründe sırasıyla $\% 2,42 \mathrm{~S}$ ve $\% 0,94 \mathrm{~S}$ elde edilmiştir. Bu sonuç ve kısa analiz sonuçları, piroliz ürünlerinden çarın kullanılmasını teorik olarak mümkün hale getirmiştir.

Piroliz deneylerinin sonuçlarının daha iyi açıklanabilmesi amacıyla, Kangal linyitine ait tüvenan linyit, tüvenan piroliz ve lave pirolizinden elde edilen çar ürünlerin FTIR analiz sonuçları Şekil 10' da gösterilmiştir.

Şekil 10'da görülen $3414 \mathrm{~cm}^{-1}$ dalga boyundaki pik, sudaki $\mathrm{OH}^{-}$gruplarına ve linyitin yapısında bulunan kil minerallerine ait olan piktir. Beklendiği gibi, piroliz sonucunda bu pikin şiddeti çar ürünlerde tüvenan linyite oranla azalmıştır. Numuneler havada kuru olduğu için, çar numunelerde görülen $3414 \mathrm{~cm}^{-1}$ pikinin numunedeki kil mineralinin adsorbe ettiği suyun sonucu olabileceği düşünülmüştür. Hidrokarbon türlerine bağlı olarak ortaya 
çıkan ve alifatik yapıyı gösteren C-H titreşim bandı ise $2920 \mathrm{~cm}^{-1}$ değerinde görülmektedir. Bu pikin çar ürünlerde neredeyse kaybolduğu belirlenmiştir. $\mathrm{Bu}$ durum piroliz işlemi sırasında birçok $\mathrm{C}$ - $\mathrm{C}$ bağın bozularak parçalandığına işaret etmektedir. Piklerin şiddetindeki azalmanın uçucu madde çıkışına bağlı olarak gerçekleştiği düşünülmektedir. $1618 \mathrm{~cm}^{-1}$, de görülen pik aramotik yapıdaki $\mathrm{C}=\mathrm{C}$ ve $\mathrm{C}=\mathrm{O}$ karbonil gerilmelerini gösteren piktir. $1430 \mathrm{~cm}^{-1}$ piki ise yapı içerisindeki metal $(\mathrm{Ca}, \mathrm{Mg}, \mathrm{Na}, \mathrm{K})$ iyonlarına ait karboksilat gruplarını göstermektedir. Bu pikte azalma görülmesi, çar ürünlerin, tüvenan linyitten daha aromatik yapıda olduğunu belirtmektedir. $1037 \mathrm{~cm}^{-1}$ piki yapıdaki kül ve külün inorganik yapısındaki Si-O-Al/Fe/Ca/Mg vb. gerilmelere aittir. Lave çarda bu pikin şiddetinde bir azalma olduğu belirlenmiştir. Bu pik, yapı içerisindeki silisli ve inorganik maddeleri gösterdiği için, zenginleştirme işleminin başarılı olduğu sonucuna varılabilir.

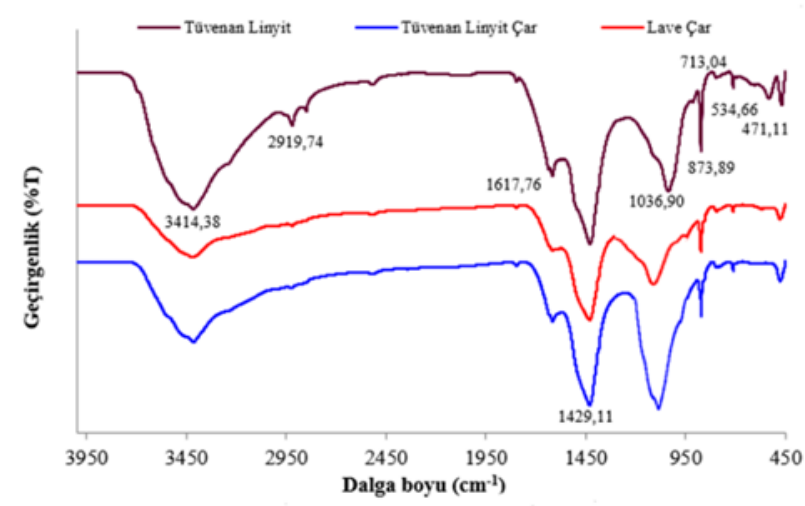

Şekil 10. Kangal linyitine ait tüvenan, tüvenan piroliz ve lave piroliz çar ürünlerinin FTIR analiz sonuçları

\section{Sonuçlar}

- Zenginleştirme işlemleri, tüvenan linyitin kül ve kükürt içeriğini azaltarak daha kaliteli teknolojik ürün elde edilmesi amacıyla gerçekleştirilmiştir. Bu amaçla, Reichert spirali kullanılarak yapılan deneyler sonucunda, tüvenan kömüre göre kül içeriği yaklaşık \%23, kükürt içeriği ise $\% 1,7$ azaltılmış olan temiz lave elde edilmiştir. Temiz kömürün kalorifik değerinde $1130 \mathrm{kcal} / \mathrm{kg}^{\prime} l \mathrm{lk}$ bir artış olduğu hesaplanmıştır.

- Tüvenan Kangal linyiti için yapılan tüm piroliz çalışmalarının sonucunda optimum şartlar; $-4,75 \mathrm{~mm}$ tane boyutu, $500^{\circ} \mathrm{C}$ piroliz sıcaklığı ve 30 dakika piroliz süresi olarak seçilmiştir. Belirlenen bu şartlarda lavenin de pirolizi gerçekleştirmiş̧tir. Zenginleștirme işlemi ile, tüvenan kömüre göre çar veriminde azalma $(\% 14,26)$, buna karşıllk sıvı ürün $(\% 11,97)$ ve gaz ürün verimlerinde $(\% 2,29)$ ise artış olduğu görülmüştür. Lave çarın kül içeriği azalırken, sabit karbon içeriği ve buna bağlı olarak kalorifik değerinin arttığı belirlenmiştir.

- Tüvenan linyit, tüvenan çar ve lave çarının her $1000 \mathrm{kcal}$ başına düşen kükürt oranları sırasıyla $\% 0,52$, $\% 0,27$ ve $\% 0,10$ olarak hesaplanmıştır. Bu sonuçlar, linyitin yıkanması gerektiğini ve kükürt açısından çevre kirliliğini en aza indirecek yakıtın elde edilebileceğinin teorik olarak mümkün olduğunu göstermiştir.

- Zenginleștirme ve piroliz çalışmaları, Kangal linyitinden kükürt uzaklaştırmanın başarılı olarak yapılabileceğini göstermiş̧tir. Çar ürünlerin kısa analizi karşılaştırıllığında, kül ve kükürt giderimi açısından kömür yıkamanın faydalı olduğu açıkça görülmüştür. Çalışma sonuçlarından, zenginleştirme işleminin piroliz ürünlerinden çar ürünün kalitesi üzerine belirgin bir şekilde olumlu yönde katk1 sağladığı anlaşılmıştır.

- Tüm bu çalışmaların sonucunda, zenginleştirme yöntemi ve piroliz ürünlerinden çar ve sıvı ürün üzerine daha ayrıntılı araştırmaların yapılmasının uygun olacağı kanaati oluşmuştur.

\section{Teșekkür}

Bu yayında sunulan araştırma, BAP-2015/34 sayılı proje kapsamında İnönü Üniversitesi Bilimsel Araştırma Projeleri Koordinasyon Birimi tarafından desteklenmiş̧ir. 


\section{Kaynaklar}

[1] Altun N.E, Hiçyılmaz C, Kök M.V. Effect of particle size and heating rate on the pyrolysis of Silopi asphaltite. J. Anal. Appl. Pyrolysis 2003; 67: 369-379.

[2] Zhang D. Thermal decomposition of coal. Encyclopedia of Life Supp. Systems (EOLSS), 2005, 261-267.

[3] Sychkov P.A, Jirnov B.S, Khajbullin A.A. Not fuel using of brown coal. Oil and Gas Business, 2009, 1-10.

[4] Miller B.G. Coal Energy Systems. San Diego, USA: Elsevier Academic Press, 2005.

[5] Ballice L. Classification of volatile products evolved from temperature-programmed pyrolysis of Soma-lignite and Şırnak-asphaltite fromTurkey. Journal of Analytical and Applied Pyrolysis 2002; 63: 267-281.

[6] Özdoğan S, Karaosmanoğlu F. Kömürün pirolizi, Kömür Özellikleri, Teknolojisi ve Çevre İlişkileri. Kural O. İstanbul: Özgün Ofset Matbaacılık A.Ş, 1998; 497-509.

[7] Ekinci E, Okutan H. 1991. Piroliz-düşük sıcaklık karbonizasyonu, Kömür. Kural O. İstanbul: Özgün Ofset Matbaacılık A.Ş, 1991; 632.

[8] Aksoğan Korkmaz A. Zenginleştirme yöntemlerinin değişik linyitlerin piroliz ürün verimleri üzerine etkisi. Doktora Tezi, İnönü Üniversitesi, Malatya, Türkiye, 2017.

[9] Kemal M, Arslan V. Kömür Teknolojisi. İzmir: Dokuz Eylül Üniversitesi Mühendislik Fakültesi Yayınları, 2010.

[10] Toprak S, Yalçın Erik N. Petrographical properties and unusual features of Kangal coals, Sivas-Turkey. International Journal of Coal Geology 2011; 86: 297-305.

[11] Karayiğit A.İ, Gayer R.A, Ortac F.E, Goldsmith S. Trace elements in the Lower Pliocene fossiliferous Kangal lignites, Sivas, Turkey. International Journal of Coal Geology 2001; 47: 73-89.

[12] Altun N.E, Hiçyılmaz C. Alpagut-Dodurga atık kömürlerinin değerlendirilmesi. Türkiye 13. Kömür Kongresi; 29-31 Mayıs 2002; Zonguldak. syf. 113-123.

[13] Öney Ö, Tanrıverdi M, Çiçek T. Zonguldak ince kömürlerinin spiral ayırıcı ile zenginleştirilmesi. Türkiye 19. Kömür Kongresi; ;1-23 Mayıs 2014, Zonguldak. syf. 217-225.

[14] Wei Q, Qiang X, Yuyi H, Jiatao D, Kaidi S, Qian Y, Jincao W. Combustion characteristics of semicokes derived from pyrolysis of low rank bituminous coal. International Journal of Mining Science and Technology 2012; 22: 645-650.

[15] He Q, Wan K, Hoadley A, Yeasmin H, Miao Z. TG-GC-MS study of volatile products from Shengli lignite pyrolysis. Fuel 2015; 156: 121-128.

[16] Lievens C, Ci D, Bai Y, Ma L, Zhang R, Chen Y.J, Gai Q, Long Y, Guo X. A study of slow pyrolysis of one low rank coal via pyrolysis-GC/MS. Fuel Processing Technology 2013; 116: 85-93.

[17] Li X, Xue Y, Feng J, Yi Q, Li W, Guo X, Liu K. Co-pyrolysis of lignite and Shendong coal direct liquefaction residue. Fuel 2015; 144: 342-348. 